\title{
The Impact of Phenological and Artificial Factors on Seed Quality in a Nematode-resistant Pinus densiflora Seed Orchard
}

\author{
By H. Ozawa ${ }^{1)}$, J. Watanabe ${ }^{1)}$, H. Chen $^{2)}$, K. Isoda ${ }^{3)}$ and A. Watanabe ${ }^{3), *)}$
}

(Received 15 ${ }^{\text {th }}$ June 2007)

\begin{abstract}
To clarify the relationship between the impact of phenological and/or artificial factors on seed quality, we measured the numbers of strobili on nematode-resistant Pinus densiflora clones grown in an immature and relatively small scale $\left(700 \mathrm{~m}^{2}\right)$ seed orchard. In addition, we established the clonal identities of all ramets, identified the paternal parent of the seeds, and assessed the resistance of seedlings to nematode infection. We also clarified the quantitative differences of strobili among clones; one clone produced $86.4 \%$ and $70.8 \%$ of all male strobili and female strobili, respectively. However, given that the total contamination ratio of the orchard was $82.0 \%$, immigrant pollen had a larger impact on the success of actual crossing than phenology. Seedlings with a resistant maternal parent were resistant, even when their paternal parent was from outside the orchard. Two unselected clones were also planted in the seed orchard, one of which was not resistant and was associated with a maternal contribution of $34.7 \%$ of all seed stock. These findings suggest that, despite having a large impact on the crossing, immigrant pollen has a minor impact on seed resistance. Conversely, unselected and nonresistant clones have a marked impact on seed resistance. We concluded that artificial factors have larger impact on the seed quality than phenological factors in this orchard and the seeds will be of sufficient quality for supplying the market once nonresistant clones have been removed from the orchard.
\end{abstract}

Key words: nematode resistant, Pinus densiflora, pollen contamination, resistant ability, seed orchard, seed quality, SSR marker.

\section{Introduction}

One of the aims of clonal seed orchards is to facilitate the production of seeds with desirable genetic traits. Generally, crossing in seed orchards is primarily affected by phenological and/or artificial (human-inducible) factors, including quantitative variation in strobili between clones (TODA et al., 1993; MATZIRIS, 1997) and temporal asynchrony between maternal flowering and pollen shedding (GRIFFIN, 1982; ERICKSON and ADAMS, 1989; BurczyK and PART, 1997; PARATAINEN and PUlKkiNEN, 2003; OWENs et al., 2005; Slavov et al., 2005) causing differences in both the paternal (GоTO et al., 2002; CHAIX et al., 2003; MoriguCHI et al., 2004) and the

\footnotetext{
1) Fukushima Prefectural Forestry Research Centre, 1 Nishijimasaka, Narita, Asaka-machi, Koriyama 963-0112, Japan.

2) Hubei Provincial Forestry Bureau, 355 Xiongchudajie, Hongshan, Wuhan 430079, China.

3) Forest Tree Breeding Center, Independent Administrative Institution, 3809-1 Ishi, Juo, Hitachi, Ibaraki 319-1301, Japan.

*) The communicating author: A. WATANABE.

E-Mail: nabeatsu@affrc.go.jp
}

maternal (GRIFFIN, 1982; MATZIRIS, 1992; TANG and IDE, 2001) contributions to the seed stock. Another phenological factor is the immigration of pollen from outside sources (STOEHR and NEWTON, 2002), which has resulted in contamination ratios of seed orchards ranging from $2.2 \%$ to $71.2 \%$ (EL-KASSABY et al., 1989; ADAMS et al., 1997; PAKKANENN et al., 2000; Gото et al., 2002; MoRIGUCHI et al., 2004). Artificial factors contributing to contamination include mislabeling and misplanting of ramets (HARJU and MUONA, 1989; WHEELER and JECH, 1992; KAWAUCHI and Goto, 1999; Gото et al., 2005). Taken together, these studies indicate that smaller scale and/or younger seed orchards are more susceptible to these factors.

While these studies have clarified the impacts of these negative factors on actual crossing, they have not explored how these factors affect seed quality (genetic traits). Orchard managers consider the effects of these negative factors to be minor if they have only a relatively small impact on seed quality, but the acceptable limits of such decreases in quality have not yet been ascertained. In addition, it is not yet known how soon after the establishment of a seed orchard can the seed be used to supply the market.

In the present study, we examined a Pinus densiflora seed orchard comprised of clones that are resistant to the pine wood nematode (Bursaphelenchus xylophilus). Pine species are one of the most important resources for environmental conservation in Japan because pine forests constitute approximately $10 \%$ of total forested area and also because the coastal vegetation in Japan is dominated pine species. However, over the last five decades, pine species such as $P$. densiflora and $P$. thunbergii have been seriously affected by pine wilt disease caused by the pine wood nematode (FUлIмото et al., 1989). A breeding project employing nematode inoculation tests to select resistant trees from natural forests and their subsequent establishment in seed orchards was initiated in 1978 to improve the resistance of trees to the pine wood nematode (FuJimoto et al., 1989). As a result of these efforts, resistant $P$. densiflora and $P$. thunbergii seed orchards have been established in Japan. These resistant seed orchards have generally been managed on a smaller scale than the seed orchards used for the timber industry and have been used to supply the market with seeds.

Nematode resistance in Pinus spp. and the associated genetic characteristics of this resistance are still unknown. Resistance has been observed to vary among pine species (FUTAI and FURUNO, 1979); for example, resistance in $P$. thunbergii was found to be lower than in $P$. densiflora. In addition, the seed resistance of $P$. thun- 
bergii is reduced considerably by immigrant pollen (Gото et al., 2002). On the other hand, the effect of phenological and/or artificial factors on the seed resistance in $P$. densiflora is still unknown.

In order to assess the effect of these factors on seed quality (nematode resistance), we selected a relatively small and young resistant $P$. densiflora seed orchard that was susceptible to these factors and conducted the following field measurements and DNA analyses using SSR or microsatellite markers: 1) flowering characteristics of the clones; 2) clonal identity of all ramets; 3 ) crossing dynamics; 4) seed resistance.

\section{Materials and Methods}

\section{Seed orchard}

The nematode-resistant $P$. densiflora seed orchard investigated was located in central Japan $\left(37^{\circ} 51^{\prime} \mathrm{N}\right.$, $140^{\circ} 53^{\prime} \mathrm{E}, 68 \mathrm{~m}$ a.s.l.) (Fig. 1). According to GIERTYCH (1965), the $700-\mathrm{m}^{2}$ seed orchard was initially laid out as follows: the clonal ramets of ten resistant clones were planted at $3.5-\mathrm{m}$ intervals throughout the orchard in 1998 (Table 1). Another six resistant clones were planted in 2002 to give a total of 422 ramets in 2006 .

\section{Phenological measurements}

The number of male and female strobili on five ramets of each clone was counted in May 2003 (Fig. 2a). All of the cones from these ramets were collected in October 2004 , and the weight of the seeds collected from these cones was measured.

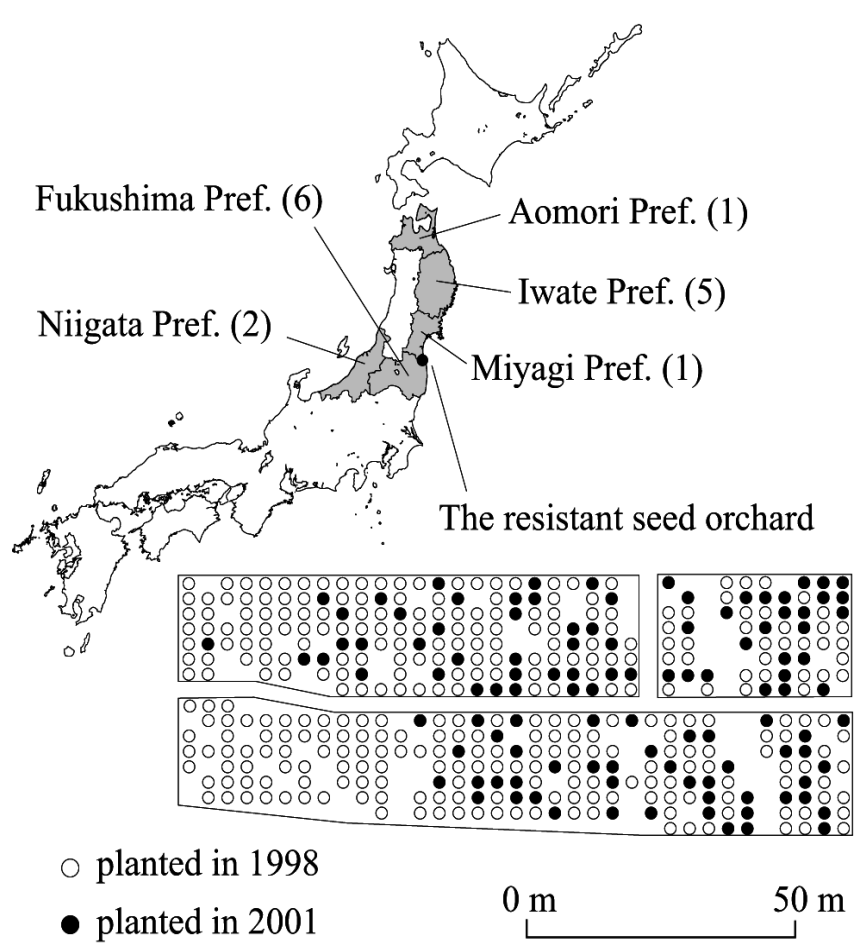

Figure 1. - Location and ramet allocation of the nematoderesistant $P$. densiflora seed orchard in Fukushima Prefecture. Gray areas indicate prefectures from which ortets were selected and figures in parenthesis show the number of ortets from which clones were derived for planting in the seed orchard.

\section{Clonal identification}

DNA was extracted from several needles collected from all ramets in July 2006 using a CTAB extraction protocol (ShIRAISHI and WATANABE, 1995). Microsatellite loci were amplified using the five primer pairs, pdms 009 (WATANABE et al., 2006), pde14 (LiAn et al., 2000), bcpd006 (Gото et al., 2005), bcpd502 and bcpd222 (IsODA and WATANABE, unpublished data). Genotypes were scored on the basis of PCR product length for each locus using an ABI PRISM 3100 genetic analyzer (Applied Biosystems, USA) and GENESCAN (ver. 3.7) and GENOTYPER (ver. 2.0) genetic analysis software (Applied Biosystems).

\section{Paternal analysis}

Two to four ramets of six clones (Sanbongi-5, Kamiheii-101, Miyagi-101, Kariha-102, Iwaki-8 and Iwaki-26) were selected for paternal analysis (Fig. 2b). All of the cones from these ramets were collected in October 2004, and 100-200 seedlings per ramet were used for DNA analysis. DNA was extracted and genotyped using the methods described above. The paternal alleles of the seeds at every locus were inferred by subtracting the maternal alleles from the offspring alleles. A likelihood criterion allowing for pollen immigration was employed for the paternal parentage analysis (GERBER, 2000; CHAIX et al., 2003) using the FaMoz software program (GERBER et al., 2003).

\section{Nematode inoculation test}

The materials used for the nematode inoculation test consisted of 762 seedlings from five clones (Sanbongi-5, Ojika-102, Kariha-102, Kitakanbara-2 and Miyagi-101). Seeds were collected in 2002, and the seedlings were raised in the nursery of the Fukushima Prefectural Forest Research Centre ( $37^{\circ} 21^{\prime} \mathrm{N}, 140^{\circ} 20^{\prime} \mathrm{E}, 254 \mathrm{~m}$ a.s.l.) from 2003 to 2005 for use as the test seedlings. They were three years old at the time tests were conducted. The seedlings were transplanted into plastic pots (approx. $19 \mathrm{~cm}$ diam., $16 \mathrm{~cm}$ deep) in March 2005. The mean height of seedlings (incl. pots) was $49.1 \pm 5.2 \mathrm{~cm}$ $( \pm \mathrm{SD}, \mathrm{n}=160)$ and the mean diameter at the ground surface was approximately $10 \mathrm{~mm}$ in July 2005.

The resistance controls were 100 three-year-old, openpollinated seedlings from five clones (Sanbongi-3, Iwate104, Ichinoseki-101, Iwaizumi-101, Kitakanbara-2). The resistance of these clones was comparable to that of $P$. taeda, which is considered to be the resistance standard in Japan (TERADA et al., 1997). They were provided as one-year-old seedlings by the Forest Breeding Center in April 2004 and were raised in the same nursery as the resistance controls. The seedlings, transplanted into unglazed pots (approx. $24 \mathrm{~cm}$ diam., $21 \mathrm{~cm}$ deep) in March 2005, had a mean height (incl. pot) was 54.1 \pm 9.1 $\mathrm{cm}( \pm \mathrm{SD}, \mathrm{n}=100)$, and the mean diameter at the ground surface was approximately $12 \mathrm{~mm}$ in July 2005.

Paternal parentage and clonal identification analysis of the test seedlings were performed immediately before the test, and the methods used for DNA extraction, genotype scoring and paternal analysis were the same as those described above. 
Table 1. - The profiles of resistant clones planted in the seed orchard.

\begin{tabular}{|c|c|c|c|c|c|c|c|c|c|}
\hline \multirow{2}{*}{ Clone } & \multirow{2}{*}{ abb. } & \multirow{2}{*}{ No. } & \multicolumn{2}{|c|}{ Planting } & \multicolumn{2}{|c|}{$\mathrm{H}(\mathrm{cm})$} & \multicolumn{2}{|c|}{ DBH (cm) } & \multirow{2}{*}{$\begin{array}{l}\begin{array}{l}\text { Location of } \\
\text { ortets }\end{array} \\
\text { pref. }\end{array}$} \\
\hline & & & yr. & no. & mean & SD & mean & SD & \\
\hline Sanbongi-5 & $\mathrm{Sa}$ & 1 & 1998 & 35 & 354 & 20 & 5,5 & 0,5 & Aomori \\
\hline Ichinoseki-101 & Ic & 5 & 1998 & 33 & 289 & 28 & 3,8 & 0,8 & Iwate \\
\hline Iwaizumi-101 & Ii & 4 & 1998 & 30 & 309 & 31 & 3,4 & 1,1 & Iwate \\
\hline Iwate-104 & It & 2 & 1998 & 7 & 301 & 50 & 2,4 & 1,2 & Iwate \\
\hline Kamiheii-101 & $\mathrm{Km}$ & 6 & 1998 & 35 & 358 & 59 & 4,8 & 0,8 & Iwate \\
\hline Morioka-1 & Mo & 3 & 1998 & 14 & 246 & 45 & 2,0 & 0,7 & Iwate \\
\hline Miyagi-101 & $\mathrm{Mi}$ & 8 & 1998 & 39 & 315 & 49 & 4,4 & 1,2 & Miyagi \\
\hline Ojika-102 & $\mathrm{Oj}$ & 7 & 1998 & 35 & 254 & 41 & 3,2 & 0,9 & Miyagi \\
\hline Kariha-102 & $\mathrm{Ka}$ & 10 & 1998 & 43 & 313 & 22 & 4,9 & 0,8 & Niigata \\
\hline Kitakanbara-2 & $\mathrm{Ki}$ & 9 & 1998 & 43 & 283 & 53 & 4,2 & 1,2 & Niigata \\
\hline Iwaki-8 & I8 & 14 & 2001 & 19 & 107 & 17 & 1,8 & 0,2 & Fukushima \\
\hline Iwaki-23 & I 23 & 11 & 2001 & 27 & 97 & 32 & 1,4 & 0,4 & Fukushima \\
\hline Iwaki-25 & I25 & 13 & 2001 & 21 & 92 & 11 & 1,7 & 0,2 & Fukushima \\
\hline Iwaki-26 & I 26 & 12 & 2001 & 31 & 114 & 26 & 1,7 & 0,4 & Fukushima \\
\hline Iwaki-91 & I91 & 16 & 2001 & 5 & 89 & 25 & 1,7 & 0,2 & Fukushima \\
\hline Iwaki-94 & I94 & 15 & 2001 & 8 & 103 & 20 & 2,0 & 0,3 & Fukushima \\
\hline
\end{tabular}

The tree height and DBH was measured in 2003. Measured ramets were showed in Fig. 2 (a).

(a)

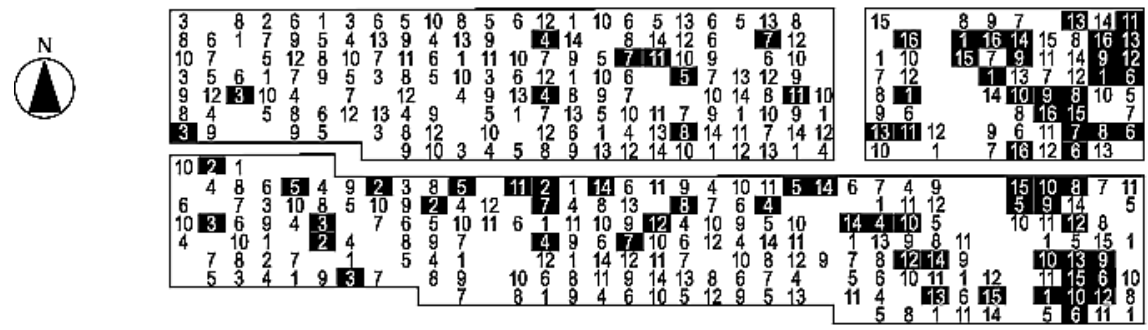

(b)

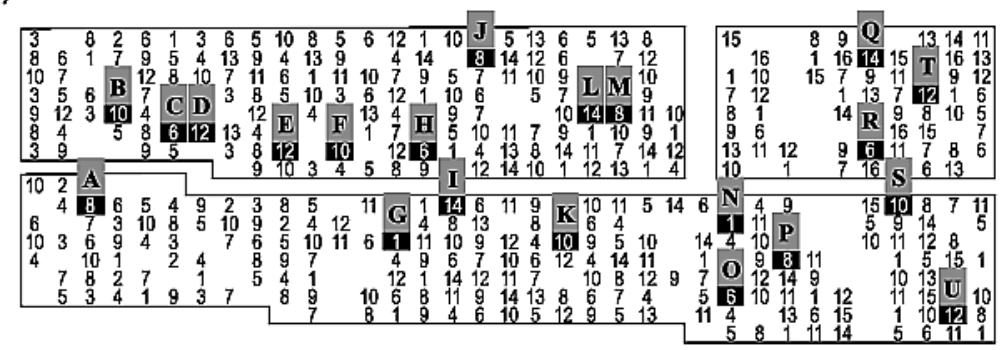

Figure 2. - Map of the resistant seed orchard with figures showing the clone names indicated in Table 1. a) Black boxes show the ramets used for strobili counts. b) Black boxes with A-U flags show ramets subjected to paternal parent analysis using seeds.

The inoculation tests were performed in a vinyl greenhouse (18.2 m long, $4.6 \mathrm{~m}$ wide, $2.7 \mathrm{~m}$ high). The test seedlings for each clone were divided into five groups using a randomized block design and a series of the resistant controls composed of four clones is positioned in the greenhouse. All of the seedlings were inoculated with $0.1 \mathrm{ml}$ of water containing 10000 pine wood nematodes (isolate name: Shimabara) using a micropipette on July 5, 2005. After inoculation, all seedlings were watered with $200-450 \mathrm{ml}$ of water via a sprinkler at 6-15 day intervals. The air temperature and humidity in the center of the greenhouse were monitored at hourly intervals at a location $35 \mathrm{~cm}$ above the floor surface. Survival was assessed ten weeks after inoculation, which is considered sufficient for the evaluation of resistant traits of the seedlings (FUлімото et al., 1989).

\section{Results}

Note that clone names are given in abbreviated form in the Results and Discussion sections (see Table 1 for definitions). 


\section{Quantities of strobili and seeds from clones}

The number of male and female strobili differed markedly among clones (Table 2). The Sa clones produced the highest number of male and female strobili at $86.4 \%$ and $70.8 \%$, respectively. Ic produced the secondhighest number of male strobili $(6.1 \%)$ and Ka produced the second-highest number of female strobili (17.8\%). Other clones produced considerably fewer strobili than the $\mathrm{Sa}$ or Ic clones. The differences in the seed products reflected differences in the numbers of female strobili. Sa produced the greatest amount of seed, $344.3 \mathrm{~g}$ in total, representing $69.5 \%$ of all seed produced.

\section{Clone identification and paternal analysis}

Except for $\mathrm{Sa}$, which consisted of three genotypes $(n=35)$, each of the clones contained only one genotype, implying that the ramets were true ramets of each clone. One Sa genotype, $\mathrm{SaA}(\mathrm{n}=18)$, was the same as

Table 2. - The amount of male and female flowers, and seed products of each clone.

\begin{tabular}{|c|c|c|c|c|c|c|c|c|}
\hline \multirow{3}{*}{ Clone } & \multicolumn{8}{|c|}{ no. of flowers and seed products / tree } \\
\hline & \multicolumn{3}{|c|}{ Male } & \multicolumn{3}{|c|}{ Female } & \multicolumn{2}{|c|}{ Seed } \\
\hline & mean & SD & $\%$ & mean & $\mathrm{SD}$ & $\%$ & total $(\mathrm{g})$ & $\%$ \\
\hline $\mathrm{Sa}$ & 567,2 & 253,4 & 86,4 & 447,6 & 114,2 & 70,8 & 344,3 & 69,5 \\
\hline Ic & 39,8 & 37,3 & 6,1 & 2,0 & 2,3 & 0,3 & 2,8 & 0,6 \\
\hline $\mathrm{Ii}$ & 0,2 & 0,4 & 0,0 & 1,2 & 1,3 & 0,2 & 0,6 & 0,1 \\
\hline It & 0 & & 0 & 7,2 & 4,8 & 1,1 & 5,9 & 1,2 \\
\hline $\mathrm{Km}$ & 0,2 & 0,4 & 0,0 & 3,4 & 2,6 & 0,5 & 2,0 & 0,4 \\
\hline Mo & 3,2 & 3,6 & 0,5 & 7,4 & 2,8 & 1,2 & 6,3 & 1,3 \\
\hline $\mathrm{Mi}$ & 6,0 & 6,4 & 0,9 & 26,0 & 11,4 & 4,1 & 70,3 & 14,2 \\
\hline $\mathrm{Oj}$ & 12,6 & 9,5 & 1,9 & 1,2 & 2,2 & 0,2 & 1,0 & 0,2 \\
\hline $\mathrm{Ka}$ & 0,2 & 0,4 & 0,0 & 112,6 & 51,8 & 17,8 & 45,0 & 9,1 \\
\hline $\mathrm{Ki}$ & 7,0 & 2,8 & 1,1 & 12,4 & 2,2 & 2,0 & 7,8 & 1,6 \\
\hline $\mathrm{I} 8$ & 1,8 & 2,4 & 0,3 & 6,0 & 1,7 & 0,9 & 7,1 & 1,4 \\
\hline $\mathrm{I} 23$ & 3,4 & 5,0 & 0,5 & 0,4 & 0,9 & 0,1 & 0 & 0 \\
\hline $\mathrm{I} 25$ & 5,0 & 5,8 & 0,8 & 0,4 & 0,5 & 0,1 & 0,2 & 0,0 \\
\hline $\mathrm{I} 26$ & 3,4 & 7,6 & 0,5 & 2,2 & 2,3 & 0,3 & 1,9 & 0,4 \\
\hline I91 & 6,2 & 5,0 & 0,9 & 0,8 & 1,3 & 0,1 & 0 & 0 \\
\hline I94 & 0,6 & 1,3 & 0,1 & 1,2 & 2,7 & 0,2 & 0,2 & 0,0 \\
\hline Total & & & & & & & 495,3 & 100 \\
\hline
\end{tabular}

Measured ramets were showed in Fig. 2 (a).

Table 3. - Results of the pollen parentage analysis of the seed.

\begin{tabular}{|c|c|c|c|c|c|c|c|c|c|c|c|c|c|c|c|c|c|c|c|c|c|c|c|c|c|c|c|c|c|c|c|c|c|c|c|c|c|}
\hline \multirow[t]{4}{*}{ Position } & \multirow[t]{4}{*}{ Clone } & \multirow{4}{*}{\multicolumn{2}{|c|}{$n$}} & \multicolumn{34}{|c|}{ Candidate of pollen parent } \\
\hline & & & & \multicolumn{4}{|c|}{ Outside } & & & & & & & & & & & & & & & & & & & & & & & & & & & & & & \\
\hline & & & & & & & & \multicolumn{30}{|c|}{ Candidate of internal pollen parent } \\
\hline & & & & & & & & \multicolumn{2}{|l|}{ SaA } & \multicolumn{2}{|l|}{$\mathrm{SaB}$} & \multicolumn{2}{|l|}{$\mathrm{SaC}$} & \multicolumn{2}{|l|}{ Ic } & \multicolumn{2}{|l|}{ Ii } & \multicolumn{2}{|c|}{$\mathrm{Km}$} & \multicolumn{2}{|l|}{ Mo } & \multicolumn{2}{|l|}{ Mi } & \multicolumn{2}{|l|}{ oj } & \multicolumn{2}{|l|}{$\mathrm{Ka}$} & \multicolumn{2}{|l|}{$\mathrm{Ki}$} & 123 & & 125 & & 126 & & 191 & \\
\hline A & Mi & 29 & $(100)$ & 26 & $(89,7)$ & 3 & $(10,3)$ & & & & & 1 & $(3,4)$ & 2 & $(6,9)$ & & & & & & & & & & & & & & & & & & & & & & \\
\hline B & Ка & 96 & $(100)$ & 89 & $(92,7)$ & 7 & $(7,3)$ & & & & & 1 & $(1,0)$ & 3 & $(3,1)$ & & & & & 2 & $(2,1)$ & & & & & & & 1 & $(1,0)$ & & & & & & & & \\
\hline c & $\mathrm{Km}$ & 86 & (100) & 81 & $(94,2)$ & 5 & $(5,8)$ & 2 & $(2,3)$ & & & & & 1 & $(1,2)$ & & & & & 1 & $(1,2)$ & & & & & & & & & & & & & & & 1 & $(1,2)$ \\
\hline D & 126 & - & (100) & & & & & & & & & & & & & & & & & & & & & & & & & & & & & & & & & & \\
\hline $\mathrm{E}$ & I26 & 14 & $(100)$ & 12 & $(85,7)$ & 2 & $(14,3)$ & 2 & $(14,3)$ & & & & & & & & & & & & & & & & & & & & & & & & & & & & \\
\hline $\mathrm{F}$ & $\mathrm{Ka}$ & 120 & (100) & 113 & $(94,2)$ & 7 & $(5,8)$ & 2 & $(1,7)$ & & & 1 & $(0,8)$ & & & & & & & 2 & $(1,7)$ & & & & & 1 & $(0,8)$ & & & & & & & & & 1 & $(0,8)$ \\
\hline G & $\mathrm{SaA}$ & 113 & (100) & 101 & $(89,4)$ & 12 & $(10,6)$ & 6 & $(5,3)$ & & & 4 & $(3,5)$ & & & & & & & & & & & 2 & $(1,8)$ & & & & & & & & & & & & \\
\hline H & $\mathrm{Km}$ & 80 & (100) & 73 & $(91,3)$ & 7 & $(8,8)$ & & & 2 & $(2,5)$ & 2 & $(2,5)$ & & & & & & & 1 & $(1,3)$ & & & & & & & & & & & 1 & $(1,3)$ & & & 1 & $(1,3)$ \\
\hline I & 18 & 94 & (100) & 82 & $(87,2)$ & 12 & $(12,8)$ & 2 & $(2,1)$ & 1 & $(1,1)$ & 5 & $(5,3)$ & & & & & 1 & $(1,1)$ & & & & & 1 & $(1,1)$ & & & & & & & 1 & $(1,1)$ & & & 1 & $(1,1)$ \\
\hline $\mathrm{J}$ & $\mathrm{Mi}$ & 73 & (100) & 61 & $(83,6)$ & 12 & $(16,4)$ & & & 3 & $(4,1)$ & 8 & $(11,0)$ & 1 & $(1,4)$ & & & & & & & & & & & & & & & & & & & & & & \\
\hline K & $\mathrm{Ka}$ & 77 & (100) & 71 & $(92,2)$ & 6 & $(7,8)$ & 1 & $(1,3)$ & 1 & $(1,3)$ & 3 & $(3,9)$ & & & & & & & & & & & 1 & $(1,3)$ & & & & & & & & & & & & \\
\hline $\mathrm{L}$ & 18 & 60 & (100) & 24 & $(40,0)$ & 36 & $(60,0)$ & 2 & $(3,3)$ & 1 & $(1,7)$ & 33 & $(55,0)$ & & & & & & & & & & & & & & & & & & & & & & & & \\
\hline M & $\mathrm{Mi}$ & 110 & (100) & 79 & $(71,8)$ & 31 & $(28,2)$ & 2 & $(1,8)$ & 1 & $(0,9)$ & 26 & $(23,6)$ & & & & & & & & & & & 1 & $(0,9)$ & & & & & & & & & & & 1 & $(0,9)$ \\
\hline $\mathrm{N}$ & $\mathrm{SaA}$ & 96 & (100) & 79 & $(82,3)$ & 17 & $(17,7)$ & 2 & $(2,1)$ & 7 & $(7,3)$ & 7 & $(7,3)$ & & & & & & & & & & & 1 & $(1,0)$ & & & & & & & & & & & & \\
\hline 0 & $\mathrm{Km}$ & 45 & (100) & 36 & $(80,0)$ & 9 & $(20,0)$ & & & 1 & $(2,2)$ & 8 & $(17,8)$ & & & & & & & & & & & & & & & & & & & & & & & & \\
\hline P & $\mathrm{Mi}$ & 57 & (100) & 50 & $(87,7)$ & 7 & $(12,3)$ & 1 & $(1,8)$ & & & 6 & $(10,5)$ & & & & & & & & & & & & & & & & & & & & & & & & \\
\hline Q & I8 & 84 & (100) & 39 & $(46,4)$ & 45 & $(53,6)$ & & & 1 & $(1,2)$ & 38 & $(45,2)$ & 1 & $(1,2)$ & 1 & $(1,2)$ & & & & & 1 & $(1,2)$ & 2 & $(2,4)$ & & & & & & & & & & & 1 & $(1,2)$ \\
\hline $\mathrm{R}$ & $\mathrm{Km}$ & 95 & (100) & 84 & $(88,4)$ & 11 & $(11,6)$ & & & 2 & $(2,1)$ & 6 & $(6,3)$ & & & & & & & 1 & $(1,1)$ & & & & & & & 1 & $(1,1)$ & & & & & & & 1 & $(1,1)$ \\
\hline $\mathrm{s}$ & Ка & 116 & (100) & 98 & $(84,5)$ & 18 & $(15,5)$ & 2 & $(1,7)$ & 7 & $(6,0)$ & & & 1 & $(0,9)$ & & & 1 & $(0,9)$ & 1 & $(0,9)$ & & & 1 & $(0,9)$ & & & 1 & $(0,9)$ & 2 & $(1,7)$ & 1 & $(0,9)$ & & & 1 & $(0,9)$ \\
\hline $\mathrm{T}$ & I 26 & 63 & $(100)$ & 36 & $(57,1)$ & 27 & $(42,9)$ & & & 2 & $(3,2)$ & 22 & $(34,9)$ & 1 & $(1,6)$ & & & & & & & 2 & $(3,2)$ & & & & & & & & & & & & & & \\
\hline U & I26 & 44 & (100) & 39 & $(88,6)$ & 5 & $(11,4)$ & & & & & 3 & $(6,8)$ & 1 & $(2,3)$ & & & & & & & & & & & & & & & & & & & & $(2,3)$ & & \\
\hline Total & & 1552 & (100) & 1273 & $(82,0)$ & 279 & $(18,0)$ & 24 & $(1,5)$ & 29 & $(1,9)$ & 174 & $(11,2)$ & 11 & $(0,7)$ & 1 & $(0,1)$ & 2 & $(0,1)$ & 8 & $(0,5)$ & 3 & $(0,2)$ & 9 & $(0,6)$ & 1 & $(0,1)$ & 3 & $(0,2)$ & 2 & $(0,1)$ & 3 & $(0,2)$ & 1 & $(0,1)$ & 8 & $(0,5)$ \\
\hline & & & & & & & $(100)$ & & $(8,6)$ & & $(10,4)$ & & $(62,4)$ & & $(3,9)$ & & $(0,4)$ & & $(0,7)$ & & $(2,9)$ & & $(1,1)$ & & $(3,2)$ & & $(0,4)$ & & $(1,1)$ & & $(0,7)$ & & $(1,1)$ & & $(0,4)$ & & $(2,9)$ \\
\hline
\end{tabular}

I26 (D) was unable to analyze because it did not have a cone. Position of the ramets were showed in Fig. 2 (b). 
Table 4. - Results of pollen parentage analysis of the inoculated seedlings.

\begin{tabular}{|c|c|c|c|c|c|c|c|c|c|}
\hline \multicolumn{2}{|c|}{ Clone } & \multirow[t]{4}{*}{$n$} & \multicolumn{5}{|c|}{ Candidate of pollen parent } & \multirow[t]{3}{*}{ UA } & \multirow[t]{2}{*}{ SU } \\
\hline & & & Total & \multicolumn{2}{|c|}{ outside } & \multicolumn{2}{|c|}{ inside } & & \\
\hline & & & no. $\%$ & & & & & & \\
\hline & A & & $40(100)$ & 40 & $(100)$ & 0 & $(0)$ & & \\
\hline \multirow[t]{2}{*}{$\mathrm{Sa}$} & B & 161 & $29(100)$ & 29 & $(100)$ & 0 & (0) & 2 & 6 \\
\hline & $\mathrm{C}$ & & $84(100)$ & 84 & $(100)$ & 0 & (0) & & \\
\hline $\mathrm{Oj}$ & & 117 & $116(100)$ & 112 & $(97,4)$ & 4 & $(2,6)$ & 1 & \\
\hline $\mathrm{Ka}$ & & 160 & $157(100)$ & 154 & $(98,1)$ & 3 & $(1,9)$ & 3 & \\
\hline $\mathrm{Ki}$ & & 161 & $158(100)$ & 157 & $(99,4)$ & 1 & $(0,6)$ & 3 & \\
\hline $\mathrm{Mi}$ & & 163 & $162(100)$ & 160 & $(98,8)$ & 2 & $(1,2)$ & 1 & \\
\hline Total & & 762 & $746(100)$ & 736 & $(98,7)$ & 10 & $(1,3)$ & & \\
\hline
\end{tabular}

Abbreviations are unable to analyze (UA) and seed parent unknown (SU).

Table 5. - Results of the nematode inoculation test.

\begin{tabular}{|c|c|c|c|c|c|c|c|}
\hline & \multirow{2}{*}{ Clone } & \multirow{2}{*}{\multicolumn{2}{|c|}{$n$}} & \multicolumn{2}{|c|}{ Dead } & \multicolumn{2}{|c|}{ Survival } \\
\hline & & & & $\%$ & $\mathrm{SD}$ & $\%$ & SD \\
\hline \multirow{8}{*}{ Seedling } & $\mathrm{Sa}$ & 161 & (39) & 58,5 & 4,1 & 41,5 & 4,1 \\
\hline & $\mathrm{SaA}$ & 40 & (14) & \multicolumn{2}{|c|}{50,0} & \multicolumn{2}{|c|}{50,0} \\
\hline & $\mathrm{SaB}$ & 29 & (5) & \multicolumn{2}{|c|}{45,8} & \multicolumn{2}{|c|}{54,2} \\
\hline & $\mathrm{SaC}$ & 84 & (18) & \multicolumn{2}{|c|}{65,2} & \multicolumn{2}{|c|}{34,8} \\
\hline & $\mathrm{Oj}$ & 117 & (22) & 45,0 & 17,6 & 55,0 & 17,6 \\
\hline & $\mathrm{Ka}$ & 160 & (19) & 47,0 & 17,8 & 53,0 & 17,8 \\
\hline & $\mathrm{Ki}$ & 161 & (39) & 51,9 & 27,1 & 48,1 & 27,1 \\
\hline & $\mathrm{Mi}$ & 163 & (34) & 58,2 & 7,3 & 41,8 & 7,3 \\
\hline Control & & 100 & & \multicolumn{2}{|c|}{60,0} & \multicolumn{2}{|c|}{40,0} \\
\hline
\end{tabular}

$\%$ of the seedling was showed the mean of five groups. \% of the control was the total of five families. There were not significant differences among groups and clones (Kruskal-Wallis test, $\mathrm{P}<0.01$ ). Figures in the brackets showed the number of uninoculated samples.

the Sanbongi-5 genotype maintained at the Forest Breeding Center. The other two genotypes, $\mathrm{SaB}(\mathrm{n}=3)$ and $\mathrm{SaC}(\mathrm{n}=14)$ did not correspond to any of the clones planted in the seed orchard or maintained by the Forest Breeding Center. SaA ramets were predominantly found on the western side of the orchard, while $\mathrm{SaC}$ ramets were mainly located on the eastern side. Ramets of SaB and $\mathrm{SaC}$ represented $4 \%$ of all the ramets planted.

Due to pollen immigration, almost all of the paternal parents of the seeds were from outside the orchard (Table 3). $\mathrm{Km}$ (C in Fig. 2b) and $\mathrm{Ka}(\mathrm{F})$ had the highest contamination ratios among all the ramets analyzed $(94.2 \%)$ and $\mathrm{I} 8(\mathrm{~L}) \mathrm{had}$ the lowest $(40.0 \%)$. The total contamination ratio of the orchard was $82.0 \%$, which meant that only $18.0 \%$ of all the analyzed seeds had a paternal parent that was a planted clone. Among the planted clones, the three Sa clones (SaA-C) contributed most to internal paternal parentage $(81.4 \%)$, with the unselected SaC clone contributing $62.0 \%$ and $\mathrm{SaA}$ and SaB contributing $9.0 \%$ and $10.4 \%$, respectively. The remaining 15 clones contributed $18.6 \%$ to the total internal paternal parentage (only $2.1 \%$ of all seeds analyzed).
Only 10 of the 1552 seeds analyzed were found to be self-fertilized, 8 from $\mathrm{Sa}(\mathrm{G}$ and $\mathrm{N}), 1$ from $\mathrm{Ka}(\mathrm{F})$, and 1 from I26 (U).

\section{Inoculation tests}

Immigrant pollen accounted for almost all of the paternal parents of the test seedlings (Table 4). Contamination ratios ranged from $97.4 \%$ (Oj family) to $100 \%$ (Sa family) and the total contamination ratio for the five families was $98.7 \%$.

The air temperature in the greenhouse ranged from 16.7 to $52.2^{\circ} \mathrm{C}$, with a mean temperature of less than $33.1^{\circ} \mathrm{C}$. The relative humidity ranged between 68.8 and $97.7 \%$, with a mean of above $68.8 \%$.

Several of the surviving seedlings did not exhibit wilting at the site of inoculation, and some actually sprouted second shoots from this point (Table 5). These seedlings were assumed to have not been adequately inoculated and were excluded from the results and analysis.

The total survival ratio of the resistant controls was $40.0 \%$. Test seedlings from the $\mathrm{Oj}, \mathrm{Ka}, \mathrm{Ki}$ and $\mathrm{Mi}$ were considered to be resistant because they had survival ratios of $41.8-55.0 \%$, which were higher than those of the resistant controls (Table 5). SaA and $\mathrm{SaB}$ seedlings from had survival ratios exceeding $50 \%$ and were considered to be resistant, while $\mathrm{SaC}$ seedlings had a survival ratio of only $34.8 \%$ and were not considered to be resistant.

\section{Discussion}

In this nematode-resistant $P$. densiflora seed orchard, we found that despite the maternal contribution of clones being markedly unequal and the crossing dynamics being strongly influenced by immigrant pollen, resistance was maintained in seedlings from resistant maternal parents. Interestingly, unselected and nonresistant clones had a greater impact on resistance than immigrant pollen, and our data showed that resistance of $P$. densiflora in this orchard was more greatly influenced by artificial factors than by phenological factors. 
Differences in strobili and seed production among clones within a seed orchard have been reported previously (MATZIRIS, 1997) and quantitative differences among strobili from different $P$. thunbergii clones are known to be genetically fixed (ToDA et al., 1993). Similarly, in this study, the number of male and female strobili produced differed greatly among clones, and this tendency was also reflected in the different quantities of seeds produced by the different clones (Table 2); $86.4 \%$ of all male strobili and $70.8 \%$ of all female strobili were borne by Sa clones. In addition, Sa produced approximately $71 \%$ of all seeds. In the P. taeda seed orchard study of BYRAM et al. (1986), more than 15 years elapsed before $60 \%$ of the clones were involved in crosses as parents producing $90 \%$ of the seed. These findings suggest that, even though the number of planted clones involved in the production of seed is likely to increase over time, a quantitative imbalance with respect to flowering will be maintained in the orchard.

Compared to the flowering bias of the clones, with a total contamination ratio of $82.0 \%$, pollen contamination had a greater impact on the seed harvested in 2004 (Table 3). This suggests that the amount of pollen around female strobili from male strobili within the seed orchard was markedly lower than the amount of immigrant pollen which has been observed to be maintained at constant levels for a few years in a Picea abies seed orchard (PAKKANEN et al., 2000). The findings suggest that if the total amount of internal pollen does not increase significantly, and if the homogeneous distribution of the surrounding forest does not change markedly, high levels of pollen contamination can be expected.

In this orchard, because the number of strobili of the six clones planted in 2002 has increased markedly over time (OzAWA et al., 2005)., it is possible that the order of seed production by each clone may change even if a quantitative flowering imbalance is maintained However, given the small size of the seed orchard and absolute internal pollen deficiency, it appears likely that a high level of contamination will be maintained in the future.

Immigrant pollen was also observed to have a considerable impact on the amount of seed harvested two years previously in 2002 (Table 4). Nevertheless, test seedlings from $\mathrm{Oj}, \mathrm{Ka}, \mathrm{Ki}$ and $\mathrm{Mi}$ were found to be more resistant than the resistant controls (Table 5), suggesting that the resistance of the seeds harvested in 2004 would be maintained, even though $82.0 \%$ of the paternal parentage was attributed to immigrant pollen.

One reason why immigrant pollen is thought to have only a slight impact on resistance is because maternally conferred resistance is more important than paternally conferred resistance. In nematode inoculation tests, the survival ratio of $P$. densiflora seedlings from parents that were both resistant was $94.0 \%$, but this ratio declined to $69.5 \%$ when the paternal parent was not resistant (HANDA et al., 1995). The $69.5 \%$ decline in the survival ratio observed by Handa et al. is greater than that observed in the resistance standard, $P$. taeda, because the general survival ratio of $P$. taeda is $30-50 \%$ (OKADA and TsudA, 1989; TAKEUCHI et al., 1989; TodA et al., 1989). In other resistant $P$. densiflora orchards, the survival ratio for many seedlings after natural crossing was generally higher than that observed in $P$. taeda (OKADA and TsudA, 1989; TAKEUCHI et al., 1989; TodA et al., 1989; ENDO and NAKAGAWA, 2005).

Another reason why immigrant pollen is thought to have only a slight impact on resistance is because some of the pollen in wild $P$. densiflora forest is shed by resistant individuals. There are numerous $P$. densiflora forests surrounding the orchard and not all have been damaged by the pine wood nematode. However, because resistant individuals represent only $0.8 \%$ of the total population in wild $\mathrm{P}$. densiflora forests, it is unlikely that all of the immigrant pollen originates from males with high resistance (FUлIмото et al., 1989).

Artificial factors also influence crossing. For example, unselected clones ( $\mathrm{SaB}$ and $\mathrm{SaC}$ ) were detected in this orchard, and although they represented only $4 \%$ of all planted ramets, they accounted for $72.4 \%$ of the total internal paternal parentage and $13.0 \%$ of the total paternal parentage. However, as the maternal parent, $\mathrm{SaB}$ only had a minor impact on resistance because the test seedlings of this clone had a higher survival ratio $(54.2 \%)$ than the controls.

But, considering that the survival ratio of widely distributed unselected $P$. densiflora seedlings is less than $30 \%$, this level of resistance is unusually high for the seedlings from unselected clones (OKADA and TsuDA, 1989; TODA, 2004). One of the reasons why the test seedlings from $\mathrm{SaB}$ exhibited higher resistance than controls or unselected individuals is that the ramets of $\mathrm{SaB}$ that were mistakenly introduced at the time of the clonal proliferation originally had higher resistance. The ten clones planted in 1998 in this orchard were selected from among populations considered to have the most desirable characteristics for the timber industry (Table 1). Specifically, these "elite" trees (and their open-pollinated seedlings) generally exhibited higher levels of resistance than unselected trees (TODA et al., 1993; ToDA, 2004).

Another unselected clone, SaC, was observed to have a marked impact as a maternal parent and most of the test seedlings obtained from $\mathrm{SaC}$ had a lower survival ratio $(34.8 \%)$ than the controls (Table 5). Given that $52.2 \%$ of the $\mathrm{Sa}$ seeds produced were $\mathrm{SaC}(84 / 161)$ (Table 2), which represented $34.7 \%$ of all seed produced $(344.3 * 0.52 / 495.3), \mathrm{SaC}$ was considered to have largest maternal contribution among all clones (Table 4). In other words, almost $35 \%$ of the total seed produced in 2004 was not resistant, which would have a serious impact on seed orchard management.

We concluded that after removing the unselected and nonresistant clones from this orchard, the seeds obtained from this young, small-scale seed orchard could be used to supply the market. But, to resolve these crossing problems it is necessary to improve the resistance of the seed as soon as possible. It is also necessary for orchard managers to implement additional measures, increasing the contribution of planted clones to seed production by employing methods such as supplemental mass pollination or artificial crossing to suppress pollen contamination (EL-KASSABY and RITLAND, 1986; ERIKSSON et al., 1995; STOEHR et al., 1998; STOEHR et al., 2006). 


\section{Literature cited}

AdAms, W. T., V. D. Hipkins, J. BurczyK and W. K. RANDALL (1997): Pollen contamination trends in a maturing Douglas-fir seed orchard. Can J For Res 27: 131-134.

BuRCZYK, J. and D. PART (1997): Male reproductive success in Pseudotsuga menziesii (Mirb.) Franco: the effects of spatial structure and flowering characteristics. Heredity 79: 638-647.

Byram, T. D., W. J. LowE and J. A. McGrIFF (1986): Clonal and annual variation in cone production in loblolly pine seed orchards. Forest Science 32: 1067-1073.

Chaix, G., S. Gerber, V. Razafimaharo, P. Vigneron, D. VerhaEgen and S. HAMon (2003): Gene flow estimation with microsatellites in a malagasy seed orchard of Eucalyptus grandis. Theor Appl Genet 107: 705-712.

Di-Giovanni, Kevan P. G. (1991): Factors affecting pollen dynamics and its importance to pollen contamination: a review. Can J For Res 21: 1155-1170.

EL-Kassaby, Y. A. and K. RITLAND (1986): The relation of outcrossing and contamination to reproductive phenology and supplemental mass pollination in a Douglas-fir orchard. Silvae Genetica 35: 240-244.

El-Kassaby, Y. A., D. RUdin and R. YAZDANi (1989): Levels of outcrossing and contamination in two Pinus sylvestris L. seed orchards in northern Sweden. Scand J For Res 4: 41-49.

ENDO, R. and S. NAKAGAWA (2005): Evaluation of families produced in a pinewood seed orchard selected through the 'Breeding Project on Resistance to Pine-wood Nematodes' (Chiba Pref.) For Tree Breed 215: 7-10 (in Japanese with English summary).

ERICKSON, V. J. and W. T. AdAMs (1989): Mating success in a coastal Douglas-fir seed orchard as affected by distance and floral phenology. Can J For Res 19: 1248-1255.

ERIKSson, U., G. JANsson, R. YAZDANi and L. WilhelmsSON (1995): Effects of supplemental mass pollination (SMP) in a young and a mature seed orchard of Pinus sylvestris. Tree Physiology 15: 519-526.

Fujimoto, Y., T. Toda, K. Nishimura, H. Yamate and S. FUYUNO (1989): Breeding project on resistance to the pine-wood nematode. An outline of the research and the achievement of the project for ten years. Bull For Tree Breed Inst 7: 1-84 (in Japanese with English summary).

FUTAI, K. and T. FURUNo (1979): The variety of resistances among pine-species to pine wood nematode, Bursaphelenchus lignicolus. Bulletin of the Kyoto university forests 51: 23-36.

Gerber, S., S. Mariette, R. Streiff, C. Bodenes and A. KRemer (2000): Comparison of microsatellites and amplified fragment length polymorphism markers for parentage analysis. Molecular Ecology 9: 1073-1048.

Gerber, S., P. Chabrier and A. KREMer (2003): FaMoz: a software for parentage analysis using dominant, codominant and unparentally inherited markers. Molecular Ecology Notes 3: 479-481.

GieRTYCH, M. M. (1965): Systematic lay-outs for seed orchards. Silvae Genetica 14: 91-94.

Goto, S., F. MiYahara and Y. IdE (2002): Monitoring male reproductive success in a Japanese black pine clonal seed orchard with RAPD markers Can J For Res 32: 983-988.

Goto, S., A. Watanabe, F. Miyahara and Y. Mori (2005): Reproductive success of pollen derived from selected and non-selected sources and its impact on the perfor- mance of crops in a nematode-resistant Japanese black pine seed orchard. Silvae genetica 54: 69-76.

Goto, S., F. MIYAHARA and Y. IDE (2002): Contribution of pollen parents to the nematode-resistance in seedlings of Japanese black pine. J Jap For Soc 84: 45-49 (in Japanese with English summary).

GRIFFIN, A. R. (1982): Clonal variations in radiata pine seed orchard. I. Some flowering, cone and seed production traits. Aust J For Res 12: 295-302.

Handa, T., K. KatOH, T. UEKI and K. Kanamura (1995): The decline of the resistant ability of the resistant clone crossing with non-resistant pollen. Trans. 106rd Mtg. Jpn. For. Soc.: 295-296 (in Japanese). ${ }^{*}$

HARJU, A. and O. MuONA (1989): Background pollination in Pinus sylvestris seed orchards. Scand J For Res 4: 513-520.

KAWAUCHI, H. and S. Goto (1999): Monitoring clonal management in nematode-resistant Japanese black pine seed orchard in Kagoshima Prefecture. J Jpn For Soc 81: 338-340 (in Japanese with English summary).

Lian, C., M. Miwa and T. Hogetsu (2000): Isolation and characterization of microsatellite loci from the Japanese red pine, Pinus densiflora. Mol Ecol 9: 1186-1187.

MATZIRIS, D. (1992): Variation in cone production in a clonal seed orchard of black pine. Silvae Genetica 42: 136-141.

MATZIRIS, D. (1997): Variation in growth, flowering and cone production in a clonal seed orchard of Aleppo pine grown in Greece. Silvae Genetica 46: 224-228.

Moriguchi, Y., H. TAIRA, N. TANi and Y. Tsumura (2004): Variation of paternal contribution in a seed orchard of Cryptomeria japonica determined using microsatellite markers. Can J For Res 34: 1683-1690.

OKADA, S. and T. TsUdA (1989): Selection of resistant pine trees to the pine-wood nematode in Kinki and Setonaikai. Bull For Tree Breed Inst 7: 85-118 (in Japanese with English summary).

Owens, J. N., J. BenNetT and S. L'Hirondelle (2005): Pollination and cone morphology affect cone and seed production in lodepole pine seed orchards. Can J For Res 35: 383-400.

Ozawa, H., H. L. Chen, J. Watanabe and A. Watanabe (2005): The vision of breeding project of pine-wood resistant to nematode in Fukushima prefecture. For Tree Breed 217: 1-5 (in Japanese with English summary).

Pakkanen, A., T. NikKanen and P. Pulkkinen (2000): Annual variation in pollen contamination and outcrossing in a Picea abies seed orchard. Scand J For Res 15:399-404.

Paratainen, A. and P. Pulkkinen (2003): Flowering and Airborne Pollen Occurrence in a Pinus sylvestris Seed Orchard Consisting of Northern Clones. Scand J For Res 18: 111-117.

ShIRAISHI, S. and A. WATANABE (1995): Identification of chloroplast genome between Pinus densiflora Sieb. et Zucc and $P$. thunbergii Parl. based on the polymorphism in $r b c \mathrm{~L}$ gene. J Jap For Soc 77: 429-436 (in Japanese with English summary).

Slavov, G. T., G. T. Howe and W. T. Adams (2005): Pollen contamination and mating patterns in a Douglas-fir seed orchard as measured by simple sequence repeat markers. Can J For Res 35: 1592-1603.

Stoehr, M., H. Mehl, G. Nicholson, G. Pieper and C. NEWTON (2006): Evaluating supplemental mass pollination efficacy in a lodgepole pine orchard in British Columbia using chloroplast DNA markers. New Forests 31: 83-90. 
Stoehr, M. U., B. L. Orvar, T. M. Vo, J. R. Gawley, J. E. WeBber and C. H. NewTON (1998): Application of a chloroplast DNA marker in seed orchard management evaluations of Douglas-fir. Can J For Res 28: 187-195.

Stoenr, M. U. and C. H. Newton (2002): Evaluation of mating dynamics in a lodgepole pine seed orchard using chloroplast DNA markers. Can J For Res 32: 469-476.

Stoenr, M. U., J. E. Webber, C. C. A. Hollefreund and R. A. PAinter (2004): Potential pollen contamination effects on progeny from an off-side Douglas -fir seed orchard: 9-year field results. Can J For Res 34: 981-984.

TAKeuchi, H., H. Handa, T. Ohguro and M. OkAmuRa (1989): Selection of resistant pine trees to the pine-wood nematode in Shikoku. Bull For Tree Breed Inst 7: 119-143 (in Japanese with English summary).

TANG, D. Q. and Y. IDE (2001): Genetic variation in fruitfulness in a Hinoki (Chamaecyparis obtusa Endl.) seed orchard and its impact on the maintenance of genetic diversity in seedlots. Journal of Forest Research 6: 67-72.

Terada, M., T. Toda and T. Noguchi (1997): The selection of the nematode-resistant candidates from the damaged forest in the cold district. The control trees of the inoculation test in the breeding project on resistance to pine- wood nematodes in Tohoku. Bull Tohoku For Tree Breed Inst 27: 57-58 (in Japanese). ${ }^{*}$

Toda, T., Y. Fujimoto, K. Nishimura, H. Yamate and S. FuYuno (1989): Selection of resistant pine trees to the pine-wood nematode in Kyushu. Bull For Tree Breed Inst 7: 145-178 (in Japanese with English summary).

ToDA, T. (2004): Studies on the breeding for resistance to the pine wilt disease in Pinus densiflora and $P$. thunbergii Bull For Tree Breed Inst 20: 83-217 (in Japanese with English summary).

Toda, T., M. TAJime, K. Nishimura and H. TAKeuchi (1993): Resistance breeding to the pine wood nematode in Kyushu district. - Progress of study after selection of the resistance clones - Bull For Tree Breed Inst 11: 37-88 (in Japanese with English summary).

Watanabe, A., M. G. Iwaizumi, M. Ubukata, T. Kondo, C. LIAN and T. HoGETU (2006): Isolation of microsatellite markers from Pinus densiflora Sieb. et Zucc. using a dual PCR techniques. Mol Ecol Notes 6: 80-82.

WheELER, N. C. and K. S. JECH (1992): The use of electrophoretic markers in seed orchard research. New Forests 6: 311-328.

*) The titles are approximate translations of the original Japanese title by the authors of this paper.

\title{
Genetic Variation in Seed Size and Germination Patterns and their Effect on White Spruce Seedling Characteristics
}

\author{
By S. Carles ${ }^{1), *}$, M. S. Lamhamedi ${ }^{2)}$, J. Beaulieu ${ }^{3)}$, D. C. Stowe ${ }^{1)}$, F. Colas $^{2)}$ and H. A. Margolis ${ }^{1)}$
}

(Received $4^{\text {th }}$ December 2007)

\begin{abstract}
We determined the degree to which families differ in seed and germination characteristics and examined the extent to which these characteristics influence the early growth of 75 open-pollinated white spruce families. Seed

\footnotetext{
1) Centre d'étude de la forêt (CEF), Faculté de foresterie, de géographie et de géomatique, Pavillon Abitibi Price, Université Laval, 2405 rue de la Terrasse, Québec, QC, G1V 0A6, Canada. des Ressources naturelles et de la Faune, 2700 rue Einstein, Québec, QC, G1P 3W8, Canada. an Wood Fibre Centre, 1055 rue du P.E.P.S., P.O. Box 10380, Sainte Foy, Québec, QC, G1V 4C7, Canada. 418-656-5262. E-Mail: sylvie.carles@sbf.ulaval.ca
}

2) Direction de la recherche forestière, Forêt Québec, ministère

3) Natural Ressources Canada, Canadian Forest Service, Canadi-

*) Corresponding Author: Sylvie Carles. Tel: 418-656-2629, Fax:
\end{abstract}

characteristics (1000-seed weight, length, width, area, volume) were measured for 400 seeds per family. Germination variables (germination capacity, peak value, germination value) were determined for each of the 75 families under controlled conditions and germination patterns were modelled using the Weibull function. Seedling characteristics (height, diameter, shoot and root dry weights) were measured at the end of the first and second growing seasons under standard nursery cultural practices. Statistically significant family variation $(p<0.0001)$ was found for all seed characteristics and germination variables measured. The between-family variance explained $23 \%$ to $98 \%$ of the total variance of morphological and physiological seed characteristics. Family differences at the seed stage explained up to $33 \%$ (root dry weight) and $12 \%$ (shoot dry weight) of the family differences observed at the one-year and two-year seedling stages, respectively. Since, in this study based 